\title{
Özel ve Devlet Huzurevleri Menülerinin Kalite ve Yeterlilik Açısından Değerlendirmesi
}

\author{
Evaluation of Private and Public Nursing Homes’ Menus Quality and Adequacy
}

\author{
Yağmur Demirel ${ }^{1}$, Saniye Bilici², Eda Köksal ${ }^{3}$
}

Geliş tarihi/Received: $30.02 .2018 \cdot$ Kabul tarihi/Accepted: 09.04.2018

\section{ÖZET}

Amaç: Bu çalışma özel ve devlete bağlı hizmet veren huzurevlerinde uygulanan menülerin kalite kriterlerine uygunluğu ve beslenme yönünden yeterliliğini değerlendirmek amacıyla planlanıp yürütülmüştür.

Gereçve Yöntem: Çalışmada 3 ilde (İstanbul, Ankara, İzmir) 3 özel ve 3 devlet olmak üzere 6 huzurevinin 21 günlük dönüşümlü menülerinin kalite kriterlerine uygunluğu araştırıcılar tarafından geliştirilen bir anket ile değerlendirilmiştir. Menülerin enerji ve besin ögeleri yeterliliklerinin değerlendirilmesinde Diyet ile Referans Alım (DRI) önerilerinin \%100’ünü karşllama durumu yeterli olarak kabul edilmiştir.

Bulgular: Menülerin kalite göstergelerine göre puanlarının ortalaması, özel huzurevleri ve devlet huzurevleri için sırasıyla $6.3 \pm 2.52$ ve $7.3 \pm 0.56$ olarak bulunmuştur ( $p>0.05$ ). Özel ve huzurevi menülerinin kalsiyum, folat, posa ve karbonhidrat yönünden yetersiz, enerji, protein, $C$ vitamini ve demir açısından yeterli olduğu saptanmıştır. Menülerin enerjiden gelen yağ yüzdeleri de yüksek bulunmuştur.

Sonuç: Menülerin planlandıktan sonra kalite kriterleri ve beslenme yönünden yeterliliklerinin değerlendirilerek gerekli iyileştirmelerin yapılması yaşlılara yönelik verilen beslenme hizmet kalitesini arttırabilir.

Anahtar kelimeler: Huzurevi, menü kalite kriterleri, makro besin ögesi, mikro besin ögesi

\section{ABSTRACT}

Aim: This study was conducted to evaluate the menus served in public and private nursing homes in terms of menu quality items and nutritional adequacy.

Material and Methods: In this study, 6 nursing homes (3 state, 3 private) from 3 provinces (Istanbul, Ankara, İzmir) 21-day rotation menus were evaluated via a questionnaire developed by the researchers. In the assessment of adequacy of energy and nutrients contents of menus the $100 \%$ of the Dietary Reference Intakes (DRI) was accepted as sufficient.

Results: The mean scores of the menus according to the quality indicators were found as $6.3 \pm 2.52$ and $7.3 \pm 0.56$ for the private nursing homes and state nursing homes respectively ( $>$ 0.05). The calcium, folic acid, fiber and carbohydrate contents of both public and private nursing homes' menus are found insufficient while the energy, protein, vitamin C and iron contents were sufficient. Also, the fat content of the menus were found high.

Conclusion: After the menus are planned, making the necessary improvements by evaluating the menu quality and nutritional adequacy can increase the quality of the nutrition services offered for the elderly.

Keywords: Nursing home, menu, quality criteria, macro nutrients, micro nutrients

1. İletişim/Correspondence: İstanbul Arel Üniversitesi, Sağlık Bilimleri Yüksekokulu, Beslenme ve Diyetetik Bölümü, İstanbul, Türkiye • E-posta: dyt.yagmur.demirel@ outlook.com

으 https://orcid.org/0000-0003-3877-3183
2. Gazi Üniversitesi, Sağllk Bilimleri Fakültesi, Beslenme ve Diyetetik Bölümü, Ankara, Türkiye

이 https://orcid.org/0000-0002-1235-0329

3. Gazi Üniversitesi, Sağlık Bilimleri Fakültesi, Beslenme ve Diyetetik Bölümü, Ankara, Türkiye

(i) https://orcid.org/0000-0002-7930-9910 


\section{GíRiş}

Yaşlanma, tüm canlılarda görülen, tüm işlevlerin azalmasına neden olan, sürekli devam eden evrensel bir süreç olup psikolojik, moleküler, fiziksel ve hücresel değişimleri kapsayan çok yönlü bir süreçtir (1). Yaşlanma sonucunda vücutta fiziksel değişimler meydana gelmektedir. $\mathrm{Bu}$ değişimler yaşlı bireylerde kronik hastalıkların görülme riskini arttırmaktadır. Yaşlı bireylerde kronik hastalıkların olması besin kısıtlamasıyla birlikte yaşlı bireyin işlevsel kapasitesinin de azalmasina neden olmakta ve yaşam kalitesini olumsuz şekilde etkilemektedir (2). Yaşlanmayla birlikte besin gereksinmeleri değişiklik göstermektedir. Yaşlıların, gençlerle benzer besin ögelerine (yağ, proteinler, vitaminler ve mineraller) gereksinmeleri bireysel özelliklerine göre farklılıklar göstermektedir. Bazı besin ögeleri gereksinimi yaşlılarda değişmezken, bazılarının gereksinimi artmaktadır (3). Yaşlı bireyler, genç bireylere göre daha kötü beslenme durumuna ve beslenme alışkanlıklarına sahiptir. Aynı zamanda yaşlı bireyler, yetersiz ve dengesiz beslenmelerinin yanı sıra iştah azalmasına bağlı oluşabilecek sağlık sorunları açısından da daha yüksek risk altındadır $(4,5)$. Yaşlılık döneminde yeterli ve dengeli bir şekilde beslenmenin sağlanması, sağlığın geliştirilmesi ve iyileştirilmesi hastalıklara karşı korunma dolayısıyla yaşam kalitesi ve süresinin arttırılmasında büyük bir önem taşımaktadır (2).

Yaşlı bireylerin beslenme, dinlenme, barınma gibi gereksinimlerinin zamanında ve uygun düzeyde karşılanması amacıyla kurulan huzurevleri, toplumumuzda giderek azalmakta olan aile desteğinin yerine geçen kurumsal bakım hizmeti modelinin en önemli unsuru haline gelmiştir (6). Huzurevlerinde yaşlı beslenme programlarının amacı, açlık ve besin güvencesizliğini azaltmak, yaşlı bireylerin sosyalleşmesini güçlendirmek, sağlık ve iyilik halini yükseltmek, yetersiz ve dengesiz beslenme ve sedanter yaşamdan kaynaklanan hastalıkları geciktirmektir (7). Bu çalışma, özel ve devlete bağlı hizmet veren huzurevlerinde uygulanan menülerin kalite kriterlerine uygunluğu ve beslenme yönünden yeterliliğini değerlendirmek amacıyla planlanıp yürütülmüştür.

\section{GEREÇ VE YÖNTEM}

Çalışmada, Türkiye’nin üç büyük şehri olan İzmir, Ankara ve İstanbul'da bulunan toplam 3 özel ve 3 devlete bağlı hizmet veren huzurevinin 21 günlük dönüşümlü uygulanan menüleri değerlendirmeye alınmıştır. Çalışmada kullanılan menü planlama kalite göstergeleri, Crogan ve arkadaşlarının (9) geliştirdiği FoodEx-LTC anketi ve Capra ve arkadaşlarının (10) geliştirdiği memnuniyet anketi temel alınarak araştırıcılar tarafından yeni bir anket geliştirilmiştir. Menü kalite göstergeleri dış etmenler (mevsime ve maliyete uygunluk), duyusal özellikler (renk, kıvam, sıcaklık ve tat uyumu), iç etmenler (ham madde ve pişirme yöntemi uyumu) ve öğünler arası (öğle-akşam ve önceki-sonraki gün uyumu) uyum başlıkları altında toplamda 10 değişken sorgulanarak değerlendirilmiştir. Değerlendirmedeki kesişim noktaları benzer çalışmalar yanında kurum sayısının azlığına bağlı olarak \%50 üzerinden belirlenmiştir. Buna göre menülerin 10 puan üzerinden değerlendirilmesi sonucunda, 0-5 puan aralığında olan menüler kötü, 6-8 puan aralığında olan menüler orta olarak değerlendirilirken, 9-10 puan aralığında olan menüler ise kaliteli menü olarak değerlendirilmiştir.

Menülerin bir porsiyonu için enerji ve besin ögesi içerikleri toplu beslenme hizmetlerine özgü kullanilan standart yemek tarifeleri ve porsiyon ölçüleri kullanılarak (8), Beslenme Bilgi Sistemi (BEBİS) programında hesaplanmıştır (11). Yeterliliğin değerlendirilmesinde Diyet ile Referans Alım (DRI) önerileri kullanılmış ve DRI'nın \%100’ü yeterli olarak kabul edilmiştir (12).

\section{İstatistiksel Değerlendirme}

Araştırmada SPSS 21.0 paket programı kullanılmıştır. Verilerin değerlendirilmesinde sayı (n), yüzde (\%), ortalama $(\overline{\mathrm{X}})$, standart sapma (S), analizinde ise ki- 
kare testi uygulanmıştır. İstatistiksel olarak 0.05’lik alfa hatası anlamlı kabul edilmiştir.

\section{BULGULAR}

Menülerin kalite göstergelerine göre ortalama puanları, özel ve devlet huzurevleri için sırasıyla $6.3 \pm 2.52$ ve $7.3 \pm 0.56$ puan olarak bulunmuştur ( $p>0.05)$. Tüm huzurevlerinin menülerinin mevsime uygun olarak hazırlanma konusunda oldukça yetersiz olduğu, öğünlerin birbiri içerisinde ve günler arasında benzer içerikli yemekler nedeniyle çeşitlilik sağlamada olumsuzluklar olduğu saptanmıştır (Tablo 1).

Enerji ve besin ögeleri yeterlilikleri değerlendirildiğinde, enerjinin proteinden gelen oranı \%17.0 \pm 1.1 olarak saptanmıştır. Bununla birlikte enerjinin yağdan gelen oranı $\% 36.8 \pm 1.5$ iken, karbonhidrattan gelen oranı $\% 46.2 \pm 2.0$ ile önerilen düzeyin altındadır. Özel huzurevlerindeki menülerde enerjinin $\% 17.3 \pm 0.58$ 'i proteinden, $\% 45.4 \pm 2.00$ 'si karbonhidrattan ve $\% 37.7 \pm 1.53$ 'ü yağdan sağlanmaktadır. Devlet huzurevlerindeki menülerde ise enerjinin $\% 16.7 \pm 1.53$ 'ünün proteinden, $\% 47.3 \pm 1.53$ 'ünün karbonhidrattan ve $\% 36.0 \pm 1.00$ 'inin yağdan sağlandığı belirlenmiştir (Tablo 2).

Yaşlı bireylere huzurevlerinde sunulan menülerin günlük içerdiği enerji ve yaşlı bireylerin günlük gereksinimlerinin yüzde ne kadarını karşıladığı incelendiğinde, özel ve devlet huzurevlerindeki menülerin sirasıyla 2167.0 \pm 242.00 kkal (DRI= $\% 112.33 \pm 12.50)$ ve $2316.0 \pm 224.16 \mathrm{kkal}$ (DRI=

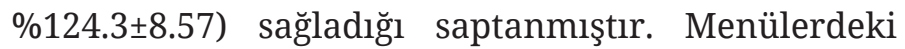
protein miktarı ve günlük gereksinimlerini karşılama yüzdesi (\%) değerlendirildiğinde ise, özel huzurevlerinde bu değer $87.5 \pm 11.53$ g (DRI=

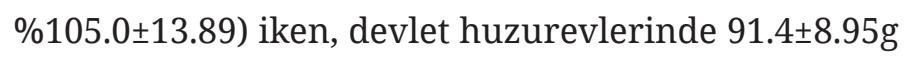
(DRI= \%109.6 \pm 11.15$)$ olarak belirlenmiştir.

Yaşlı bireylerin günlük alması gereken besin ögeleri (yağ, karbonhidrat, posa, folat, C vitamini, kalsiyum ve demir) bakımından özel huzurevleri menülerinin yeterlilikleri (DRI\%) değerlendirildiğinde, yă̆ (\%141.0 \pm 23.25$), \quad$ C vitamini $\quad(\% 127.3 \pm 72.76) \quad$ ve demir (\%127.3 \pm 19.21$)$ fazla miktarda, karbonhidrat (\%86.3 \pm 7.09$)$, posa $(\% 94.6 \pm 16.65)$, folat $(\% 90.6 \pm 15.82)$ ve kalsiyum $(\% 87.3 \pm 28.91)$ bakımından menülerin yetersiz olduğu belirlenmiştir. Devlet huzurevi menülerinin yă̆ $\quad(\% 154.0 \pm 20.07), \quad$ C vitamini

Tablo 1. Menülerin kalite göstergelerine göre puanları

\begin{tabular}{|c|c|c|c|c|c|c|c|c|}
\hline \multirow[b]{2}{*}{$\begin{array}{l}\text { Kalite } \\
\text { göstergeleri }\end{array}$} & \multicolumn{8}{|c|}{ Kalite İndikatör Puanları } \\
\hline & $\begin{array}{c}\text { Özel } \\
\text { Huzurevleri } \\
\bar{X} \pm S\end{array}$ & $\begin{array}{c}\text { Ankara } \\
\text { Puan }\end{array}$ & $\begin{array}{c}\text { İstanbul } \\
\text { Puan }\end{array}$ & $\begin{array}{l}\text { İzmir } \\
\text { Puan }\end{array}$ & $\begin{array}{c}\text { Devlet } \\
\text { Huzurevleri } \\
\overline{\mathrm{X}} \pm \mathrm{S}\end{array}$ & $\begin{array}{l}\text { Ankara } \\
\text { Puan }\end{array}$ & $\begin{array}{c}\text { İstanbul } \\
\text { Puan }\end{array}$ & $\begin{array}{l}\text { İzmir } \\
\text { Puan }\end{array}$ \\
\hline Diş faktörler & $0.3 \pm 0.56$ & 1 & 0 & 0 & $1.0 \pm 0.00$ & 1 & 1 & 1 \\
\hline Mevsime uygunluk & & 0 & 0 & 0 & & 0 & 0 & 0 \\
\hline Maliyet uygunluğu & & 1 & 0 & 0 & & 1 & 1 & 1 \\
\hline Duyusal özellikler & $3.6 \pm 0.56$ & 4 & 3 & 4 & $4.0 \pm 0.00$ & 4 & 4 & 4 \\
\hline Renk uyumu & & 1 & 0 & 1 & & 1 & 1 & 1 \\
\hline Kıvam uyumu & & 1 & 1 & 1 & & 1 & 1 & 1 \\
\hline Sicaklık & & 1 & 1 & 1 & & 1 & 1 & 1 \\
\hline Tat uyumu & & 1 & 1 & 1 & & 1 & 1 & 1 \\
\hline İç faktörler & $1.3 \pm 0.56$ & 2 & 1 & 1 & $1.3 \pm 0.56$ & 2 & 1 & 1 \\
\hline Ham madde uyumu & & 1 & 0 & 0 & & 1 & 1 & 0 \\
\hline Pişirme yöntemi uyumu & & 1 & 1 & 1 & & 1 & 0 & 1 \\
\hline Öğünler arası uyum & $1.0 \pm 1.00$ & 2 & 0 & 1 & $1.0 \pm 0.00$ & 1 & 1 & 1 \\
\hline Öğle-akşam & & 1 & 0 & 1 & & 1 & 1 & 1 \\
\hline Önceki-sonraki gün & & 1 & 0 & 0 & & 0 & 0 & 0 \\
\hline Toplam kalite puanı & $6.3 \pm 2.52$ & 9 & 4 & 6 & $7.3 \pm 0.56$ & 8 & 7 & 7 \\
\hline
\end{tabular}


Tablo 2. Menülerin enerjiden gelen makro besin ögeleri yüzde değerleri

\begin{tabular}{lccc}
\hline & \multicolumn{2}{c}{ Enerjiden gelen makro besin ögesi yüzdeleri (\%) } \\
\cline { 2 - 4 } & Protein & Yağ & Karbonhidrat \\
\hline Özel Huzurevleri $(\overline{\mathrm{X}} \pm \mathbf{S})$ & $17.3 \pm 0.58$ & $37.7 \pm 1.53$ & $45.0 \pm 2.00$ \\
Ankara & $18.2 \pm 0.18$ & $39.1 \pm 0.65$ & $42.7 \pm 1.01$ \\
İstanbul & $16.8 \pm 1.32$ & $36.3 \pm 3.02$ & $46.9 \pm 3.29$ \\
İzmir & $17.0 \pm 0.51$ & $37.7 \pm 1.08$ & $45.3 \pm 1.91$ \\
Devlet Huzurevleri $(\overline{\mathrm{X}} \pm \mathbf{S})$ & $16.7 \pm 1.53$ & $36.0 \pm 1.00$ & $47.3 \pm 1.53$ \\
Ankara & $16.7 \pm 0.60$ & $37.0 \pm 0.65$ & $46.3 \pm 0.55$ \\
İstanbul & $15.1 \pm 1.95$ & $36.1 \pm 1.05$ & $48.8 \pm 1.71$ \\
İzmir & $18.2 \pm 2.11$ & $34.9 \pm 1.32$ & $46.9 \pm 2.35$ \\
Toplam Huzurevleri $(\overline{\mathrm{X}} \pm \mathbf{S})$ & $17.0 \pm 1.10$ & $36.8 \pm 1.50$ & $46.2 \pm 2.00$
\end{tabular}

Tablo 3. Menüler ile verilen günlük enerji ve besin ögesi miktarları ile DRI karşlama yüzdelerinin ortalama değerleri

\begin{tabular}{|c|c|c|c|c|c|}
\hline & \multicolumn{2}{|c|}{ Devlet Huzurevleri } & \multicolumn{2}{|c|}{ Özel Huzurevleri } & \multirow[b]{2}{*}{$\begin{array}{c}\text { DRI } \\
\text { Önerisi }\end{array}$} \\
\hline & $\begin{array}{c}\text { Menü ile verilen } \\
(\bar{X} \pm S)\end{array}$ & $\begin{array}{c}\text { DRI karşılama \% } \\
(\bar{X} \pm S)\end{array}$ & $\begin{array}{l}\text { Menü ile verilen } \\
(\bar{X} \pm S)\end{array}$ & $\begin{array}{c}\text { DRI karşılama \% } \\
(\bar{X} \pm S)\end{array}$ & \\
\hline Enerji (kkal) & $2316.0 \pm 224.16$ & $124.3 \pm 8.57$ & $2167.0 \pm 242.00$ & $112.33 \pm 12.50$ & 2046 \\
\hline Protein $(g)$ & $91.4 \pm 8.95$ & $109.6 \pm 11.15$ & $87.5 \pm 11.53$ & $105.0 \pm 13.89$ & 46 \\
\hline Karbonhidrat (g) & $126.1 \pm 11.63$ & $97.3 \pm 12.58$ & $112.2 \pm 9.10$ & $86.3 \pm 7.09$ & 130 \\
\hline Posa (g) & $23.3 \pm 4.08$ & $93.3 \pm 16.33$ & $23.7 \pm 4.10$ & $94.6 \pm 16.65$ & 25 \\
\hline Folat (mcg) & $348.2 \pm 2.28$ & $87.3 \pm 0.57$ & $364.1 \pm 63.23$ & $90.6 \pm 15.82$ & 400 \\
\hline C vitamini (mg) & $107.1 \pm 46.26$ & $119.6 \pm 51.42$ & $114.3 \pm 65.43$ & $127.3 \pm 72.76$ & 75 \\
\hline Kalsiyum (mg) & $1092.8 \pm 243.48$ & $91.1 \pm 20.29$ & $1044.6 \pm 346.92$ & $87.3 \pm 28.91$ & 1200 \\
\hline Demir (mg) & $15.1 \pm 1.04$ & $151.3 \pm 10.40$ & $12.7 \pm 1.92$ & $127.3 \pm 19.21$ & 8 \\
\hline
\end{tabular}

DRI: Diyet ile Referans Alm

(\%119.6 \pm 51.42$)$ ve demir $(\% 151.3 \pm 10.40)$ içeriğinin fazla olduğu belirlenirken, karbonhidrat (\%97.3 \pm 12.58$)$, posa $(\% 93.3 \pm 16.33)$, folat $(\% 87.3 \pm 0.57)$ ve kalsiyum $(\% 91.0 \pm 20.29)$ bakımından yetersiz olduğu belirlenmiştir.

\section{TARTIŞMA}

Toplu beslenme hizmeti veren kurumlarda kalite göstergesi olarak değerlendirilen beslenme hizmetlerine yönelik kullanılan ölçekler objektif ve sübjektif değerlendirme yapılmasında önemli araçlardır (13). Chao (14) tarafindan huzurevlerine özgü geliştirilmiş olan "Yaşlılar için Huzurevlerinde Besin ve Beslenme Bakım Göstergeleri Kontrol Listesi” kullanılarak Türkiye'de yapılan bir çalışmada huzurevlerinde uygulanmakta olan menülerin değerlendirilmesi sonucunda genel menü denetim puanı 100 puan üzerinden $62.7 \pm 15.76$ olarak bulunmuştur (15). Bu çalışmada uygulanan değerlendirme yönteminde özel huzurevleri ve devlet huzurevleri için menü denetim puanı 10 puan üzerinden sirasiyla $6.3 \pm 2.52$ ve $7.3 \pm 0.56$ puan olarak bulunmuştur. Daha önce yapılan çalışma ile değerlendirme sonuçlarının birbirine yakın olduğu belirlenmiştir.

Yaşlılık döneminde beslenme durumunu etkileyen nedenler arasında beslenme hizmetlerinin kalitesi önemli bir yere sahiptir (16). Beslenme hizmetlerinde sunulan menülerin çeşitliliği ve uyumuna bağlı olarak bireylerin besin alımı değişmekte, yetersizlikler görülebilmektedir (17). Yetersiz ve dengesiz beslenme açısından yüksek riskli gruplardan biri olan yaşlı bireylerde morbidite ve mortalite ile malnütrisyon pozitif korelasyon göstermektedir (18). Bu nedenle huzurevlerindeki beslenme hizmetleri tarafindan hazırlanan menüler enerji, makro besin ögeleri, 
posa ve vitaminler ile mineralleri yeterli düzeyde içermelidir (19). İspanya'da 6 huzurevinde yapılan bir çalışmada 252 öğünün incelendiği menülerde protein ve enerji içeriklerinin yeterli, karbonhidrat içeklerinin ise yetersiz düzeyde olduğu bildirilmiştir (20). Berner ve arkadaşları da (21) huzurevlerinde kalan 50 yaşlı bireyin diyet örüntüsünde enerjinin \%50.5'inin karbonhidratlardan, \%34.5'inin yağlardan, \%15.1'inin proteinden sağlandığını belirlemişlerdir. Finlandiya'da bir huzurevinde yapılan çalışmada yaşlı bireylere sunulan yemeklerdeki yağ miktarının yüksek olduğu belirlenmiş olup, enerjinin \%46.0'sının karbonhidrattan, \%34.7'sinin yağdan ve \%19.3'ünün proteinden sağlandığı saptanmıştır (22). Kıbrıs’ta yapılan bir çalışmada ise enerjinin proteinden gelen yüzdesi $\% 16.04 \pm 3.49$, enerjinin yağdan gelen yüzdesi $\% 34.81 \pm 7.89$ ve enerjinin karbonhidrattan gelen yüzdesi \%45.60ะ8.94 olarak saptanmıştır (23). $\mathrm{Bu}$ çalışmadan elde edilen verilerde özel ve devlet huzurevlerinin diyet örüntüsü açısından yüksek düzeyde enerji içerdiği, enerjinin karbonhidrattan sağlanan oranının düşük (\%46.2 \pm 2.0$)$, proteinden gelen yüzdesinin yeterli $(\% 17 \pm 1.1)$, yağdan gelen oranın ise yüksek olduğu $(\% 36.8 \pm 1.5)$ saptanmıştır. Toplu beslenme hizmetlerine yönelik standart yemek tarifelerindeki porsiyon başına kullanılan yağ miktarının yüksek olması, menülerdeki yağ yüzdelerinin de yüksek olmasına neden olabilmektedir.

Villarroel ve arkadaşları (24) tarafından yapılan bir çalışmada 5 huzurevinde hazırlanan menü içeriklerinin kalsiyum miktarı açısından yaşlı bireylerin gereksinmesini karşılayamayacak düzeyde yetersiz olduğu saptanmıştır. Lengyel ve arkadaşları (19) tarafından yapılmış olan bir çalışmada huzurevlerinde yaşlı bireylere sunulan menülerin yetersiz düzeyde posa, folik asit, $\mathrm{A}, \mathrm{C}$ ve $B_{6}$ vitaminleri ile demir ve kalsiyum içerdiği belirlenmiştir. Ülkemizde yapılan bir çalışmada ise menüler yaşllların $\mathrm{C}$ vitamini gereksinmesinin

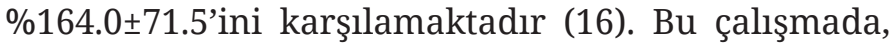
huzurevlerinde sunulan menülerin posa, kalsiyum ve folat içeriği yetersiz olarak bulunmuştur. Posa ve folat miktarının yetersizliğinin nedeni menülerde verilen sebze ve meyve miktarının yetersizliğinden kaynaklanıyor olabilir. Bu yetersizliğin giderilmesi amaciyla huzurevlerinde sunulan menülerin içeriğindeki sebze ve meyveler hem yaşlıların daha kolay tüketebileceği türlerden seçilerek hem de miktar yönünden arttırılarak bu yetersizlik önlenebilir. Yaşlıların yetersiz kalsiyum alımı, menülerde süt ve süt ürünlerine yeterince yer verilmemesinden kaynaklanıyor olabilir. Bu yetersizliğin giderilmesi amacıyla menüler, ara öğünlerde yoğurt ve benzeri kalsiyum içeriği açısından zengin ürünlerle desteklenebilir. Yapılan bir çalışmada menü içerikleri incelendiğinde $\mathrm{C}$ vitamini ve demir miktarının yeterli olduğu bulunmuştur. Aynı çalışmada, bazı huzurevlerinde yaşlılara sunulan menülerin besin ögeleri içeriğinin, yaşlıların günlük alması gereken besin ögelerini karşılamadığı belirlenmiştir (15).

Yaşlı nüfusta görülen artış, her geçen gün yaşlılara ve yaşlı politikalarına verilen önemin artmasıyla sonuçlanmaktadır. Huzurevlerinde verilen beslenme hizmetlerinden memnuniyetin ve yeterliliğin arttırılması ile yaşlı sağlığının korunması, geliştirilmesi ve/veya iyileştirilmesi hedeflenmelidir. $\mathrm{Bu}$ kapsamda yapılan çalışma, menülerin planlanmasında yemeklerin duyusal özellikleri ile içeriklerinin birbiri ile uyumunun geliştirilmesini, besinlerin mevsime uygun seçilmesi gerektiğini ortaya koymaktadir.

Yaşlı bireylere yönelik menü planlamasında bireylerin fizyolojik durumlarına bağlı olarak beslenmelerini etkileyen etmenler mutlaka göz önünde bulundurulmalıdır. Menüdeki yemeklerin birbiri ile uyumu, gerek organoleptik özellikleri gerekse de yaşlıların tüketimine uygunlukları dikkate alınmalıdır. Toplu beslenme hizmet kalitesinin arttırılması açısından menü yönetim ve denetim hizmetleri diyetisyenler tarafından sağlanmalıdır.

Çıkar çatışması - Conflict of interest: Yazarlar çıkar çatışması olmadığını beyan ederler. - The authors declare that they have no conflict of interest. 


\section{KAYNAKLAR}

1. GEBAM. Yaşlılıkta Kaliteli Yaşam. Ankara: Hacettepe Üniversitesi. 2007. Available at: www.gebam.hacettepe. edu.tr/yaslilikta_kaliteli_yasam_son.pdf. Erişim Tarihi: 05.12.2017.

2. GEBAM. Yaşlanmak Ayrıcalıktır. Ankara: Hacettepe Üniversitesi. 2011. Available at: www.gebam.hacettepe. edu.tr/bultenler/gebam2011.pdf. Erişim Tarihi: 05.12.2017.

3. Vikstedt T, Suominen MH, Joki A, Muurinena S, Soini H. Nutritional status, energy, protein and micronutrient intake of older service house residents. J Am Med Dir Assoc 2011;12(4):302-307.

4. Pirlich M, Lochs H. Nutrition in the elderly. Best Pract Res Clin Gastroenterol 2001;15(6):869-884.

5. Leslie WS, Lean ME, Woodward M. Unidentified undernutrition: Dietary intake and anthropometric indices in a residential care home population. J Hum Nutr Diet 2006;19:343-347.

6. Mavi F. Yaşlılık Politikasına Genel Bakış. Akademik Geriatri Kongresi: 20-24 Mayıs 2009-Antalya, Bildiriler. 2009, s.76-83, Antalya.

7. Kamp B J, Wellman NS. Position of the American Dietetic Association, American Society for Nutrition, and Society for Nutrition Education: Food and nutrition programs for community-residing older adults. J Nutr Educ Behav 2010;42:72-82.

8. Merdol T. Toplu Beslenme Yapılan Kurumlar İçin Standart Yemek Tarifeleri.3.Baskı. Hatiboğlu Basın ve Yayım San. Tic. Ltd. Şti, Ankara, 2003.

9. Capra S, Wright O, Sardie M, Bauer J, Askew D. The acute hospital foodservice patient satisfaction questionnaire: The development of a valid and reliable tool to measure patient satisfaction with acute care hospital foodservices. Food Res Int 2005;16:1-14.

10. Crogan NL, Evans B, Velasquez D. Measuring nursing home resident satisfaction with food and food service: Initial testing of the FoodEx-LTC. J Gerontol A Biol Sci Med Sci 2004;59(4):370-377.

11. Bebis (Beslenme Bilgi Sistemi) Nutrition Data Base Software. Data base: The German Food Code and Nutrient Data Base (BLS II.3, 1999) with additions from USDA-sr and other sources. İstanbul, 2004.

12. Institute of Medicine (IOM). Dietary Reference Intake (DRI), National Academy Press, Washington DC, 2001.

13. Saliba D. Schnelle JF. Indicators of the quality of nursing home residential care. J Am Geriatr Soc 2002;50:14211430.

14. Chao SY. Optimizing food and nutrition services in assisted living facilities for older adults: Food and Nutrition Indicators (FANCI) Study. Doktora tezi, Tufts University, Medford, 2008.

15. Ongan D. Huzurevlerinde yaşlılara sunulan beslenme hizmetlerinin değerlendirilmesi ve yaşlıların beslenme durumlarinin saptanması. Doktora tezi, Hacettepe Üniversitesi, Ankara, 2012.

16. Mudge AM, Ross LJ, Young AM, Isenring EA, Banks MD. Helping understand nutritional gaps in the elderly (HUNGER): a prospective study of patient factors associated with inadequate nutritional intake in older medical inpatients. Clin Nutr 2011;30:320-325.

17. Agarwal E, Ferguson M, Banks M, Bauer J, Capra S, Isenring E. Nutritional status and dietary intake of acute care patients: results from the Nutrition Care Day Survey 2010. Clin Nutr 2012;31:41-47.

18. Cuervo M, Ansorena D, Garcia A, Astiasaran I. Food consumption analysis in Spanish elderly based upon Mini Nutritional Assessment Test. Ann Nutr Metab 2008;52:299-307.

19. Lengyel CO, Zello GA, Smith JT. Evaluation of menu and food service practices of long-term care facilities of a health distinct in Canada. J Nutr Elder 2003;22(3):29-42.

20. Sanchez-Campillo M, Torralba C, Lopez MA, Zamora S. Strategies for improving nutritional value of the meals offered by public nursing homes for the elderly. Nutrición Hospitalaria 2010;25(6):1014-1019.

21. Berner YN, Stern F, Polyak Z. Dietary intake analysis in institutionalized elderly: A focus on nutrient density. J Nutr Health Aging 2002;6(4):237-242.

22. Souminen M, Laine A, Routasal P, Pitkala KH. Nutrient content of served food, nutrient intake and nutritional status of residents with dementia in a Finnish nursing home. J Nutr Health Aging 2004;8(4):234-238.

23. Hoca M. Kıbrıs Gazimağusa'da yaşayan yaşlı bireylerin yaşam tarzı, beslenme alışkanlıkları ve beslenme durumlarının değerlendirilmesi. Yüksek Lisans Tezi. Başkent Üniversitesi, Ankara, 2016.

24. Villarroel RM, Sangra RA. Nutritional assessment of the menus in five geriatric homes and their adaptation to the recommended intakes for the elderly population. Actividad Dietetica 2009;13(2):51-58. 